
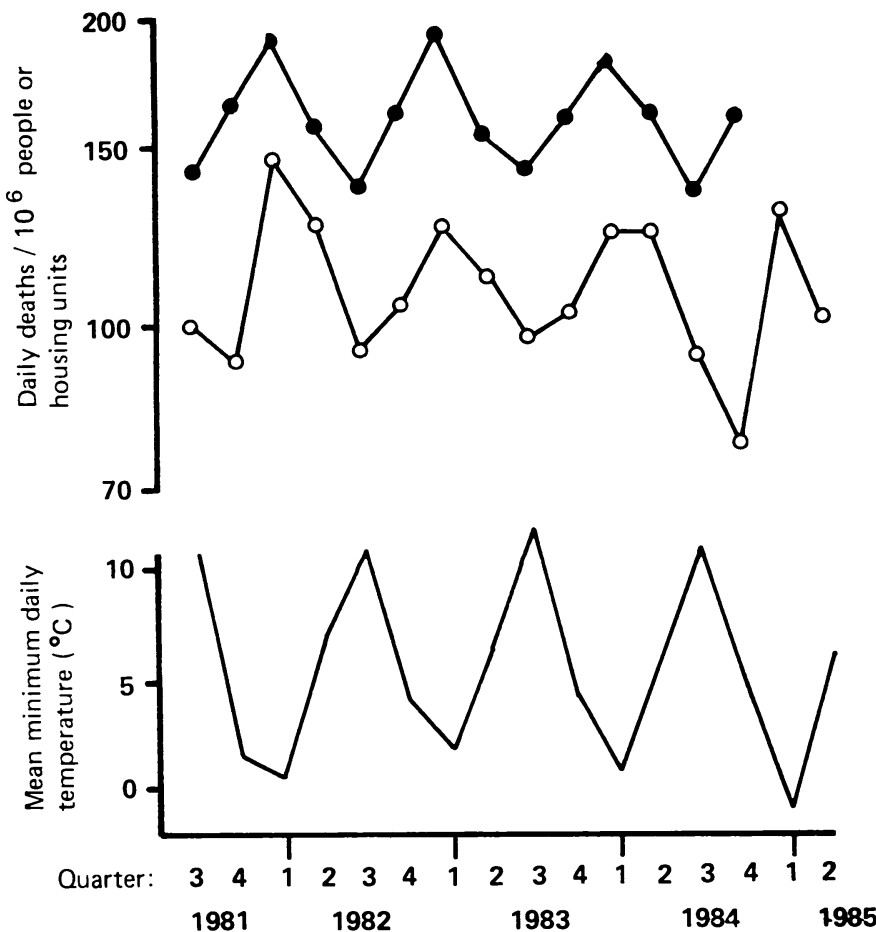

Seasonal mortality among people in warm housing (deaths $/ 10^{6}$ housing units containing $1 \cdot 2$ people/unit) and among general population of England and Wales aged 65 and over (deaths $/ 10^{6}$ population) related to mean minimum temperature at London (Kew), Birmingham, and Bradford. $\bigcirc-\bigcirc=$ People in warm housing

=General population.

exposure to cold. The simplest explanation is that though the quality of life was higher with heated housing, the beneficial effects on mortality of the high indoor temperatures were balanced by the adverse effects of increased exposure to cold outdoors. The results therefore suggest that the traditional tendency of the British to expose themselves to fresh air may be as important as poor heating in causing excess mortality during the winter. They also support previous evidence that cold weather causes death mainly by means other than hypothermia. ${ }^{4}$

This study was supported by a grant from the Medical Research Council. I am indebted to Mr John Campbell, Mr Richard Bettesworth, and staff and residents of Anchor Housing Association for their cooperation.

1 Bull GM, Morton J. Environment, temperature and death rates. Age Ageing 1978;7:210-24

2 Alderson MR. Season and mortality. Health Trends 1985;17:87-96.

3 Keatinge WR, Coleshaw SRK, Cotter F, Mattock M, Murphy M, Chelliah R. Increases in platele and red cell counts, blood viscosity, and arterial pressure during mild surface cooling: factors in mortality from coronary and cerebral thrombosis in winter. Br Med $\mathcal{F}$ 1984;289:1405-8.

4 Coleshaw SRK, Easton JC, Keatinge WR, Floyer MA, Garrard J. Hypothermia in emergency admissions in cold weather. Clin Sci 1986;70:93-4P.

(Accepted I fuly 1986)

Department of Physiology, The London Hospital Medical College, London E1 2AD

W R KEATINGE, PHD, MRCP, professor

\section{Response of secondary amyloidosis in psoriasis to treatment with etretinate and ultraviolet light}

Secondary amyloidosis is a rare but severe complication in psoriasis. Attempts at treatment, with, for example, immunosuppressive agents, have not prevented its progression, and amyloidosis has often been reported as being fatal. We report on a patient with severe psoriasis and destructive arthropathy who developed secondary amyloidosis with the nephrotic syndrome and malabsorption.

\section{Case report}

A 23 year old woman developed psoriasis of the plaque type in 1970 and psoriatic arthropathy three years later. She was treated with penicillamine and gold salts without effect, and various non-steroidal anti-inflammatory drugs induced widespread papular dermatitis. Topical steroids and tripsoralens with ultraviolet light A (PUVA baths) were tried, but her psoriasis did not improve and even worsened; for long periods she had erythrodermia. Charnley arthroplasty of the hips took place from 1980 to 1983.

In 1981 proteinuria was detected and secondary amyloidosis diagnosed from biopsy specimens of the rectal submucosa and subcutaneous fat tissue. She had begun to lose weight and her xylose absorption was abnormal. She had a consistently high inflammatory activity; erythrocyte sedimentation rate $70-100 \mathrm{~mm}$ in the first hour normal $<15 \mathrm{~mm}$ ), serum haptoglobin concentration about $5 \mathrm{~g} 1$ normal $0 \cdot 2-2 \cdot 0$. After secondary amyloidosis had been diagnosed she was treated firstly with methotrexate and then bromocriptine; neither drug cured her psoriasis or proteinuria. Her glomerular filtration rate remained normal

In June 1983 she still had ervthrodermia and also severe synovitis of the large joints, and treatment with etretinate $40 \mathrm{mg}$ daily was started. During the first three months her skin and joint symptoms improved only marginally, so PUVA baths were added. During this regimen her arthritis became inactive, and after nine months her skin was nearly healed. The acute phase reaction also decreased figure). Her proteinuria (about $3 \mathrm{~g}$ albumin day) steadily decreased and was less than $100 \mathrm{mg}$ day after more than two years of treatment with etretinate. Serum albumin concentrations increased simultaneously from 23 to 33 normal range 42-55) gl (figure). After nine months the PUVA treatment was replaced by treatment with ultraviolet light B. Her skin and joint disease remained under good control, her weight returned to normal, and her xylose absorption in December 1985 was almost normal. Amyloid deposits were not detectable. Side effects were sparse, she suffered mild xerostomia and irritation of the conjunctiva.

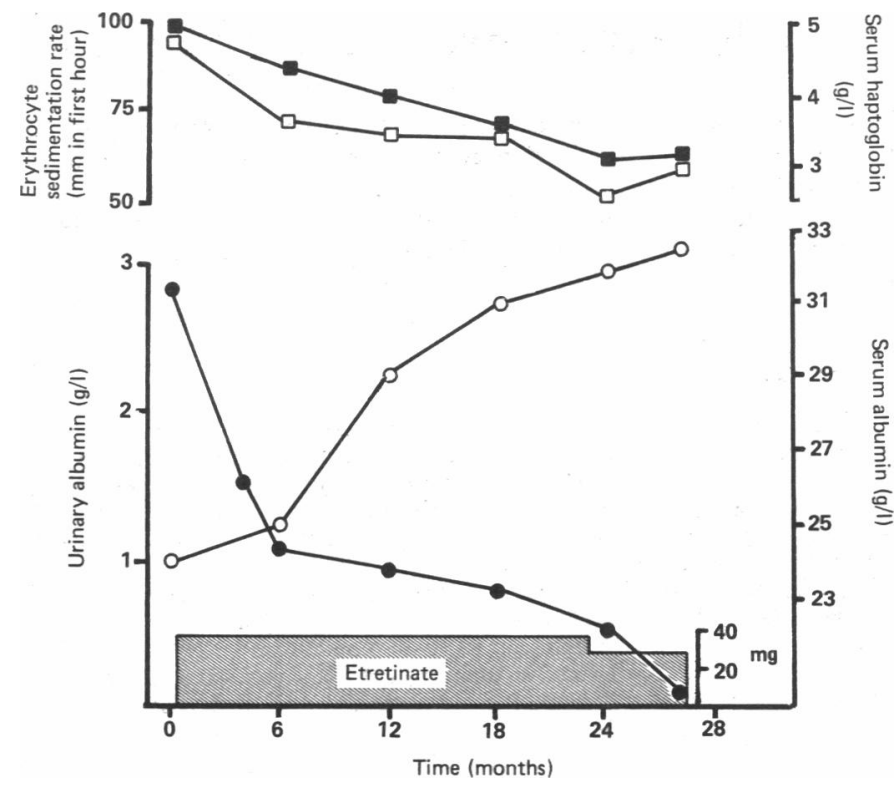

Serial measurements of erythrocyte sedimentation rate $(\mathbf{D})$, serum haptoglobin $(\square)$, urinary albumin $(\mathbf{)}$, and serum albumin $(O)$ in woman with secondary amyloidosis treated with etretinate.

\section{Comment}

Treatment with etretinate resulted in apparent total regression of secondary amyloidosis and its renal and intestinal manifestations in this patient, and we believe that the outcome was not simply spontaneous. Her clinical condition due to amyloidosis had been steadily deteriorating with time, and previous treatments with other drugs had not had any effect. Although the excellent outcome was probably mostly due to etretinate, the combined treatment with PUVA baths and ultraviolet light B possibly contributed to the psoriasis and amyloidosis being brought under control.

The beneficial effect of retinoids in skin and joint manifestations of psoriasis is well documented. ${ }^{1}$ The possible mechanisms of their action include their antikeratinising effect, anti-inflammatory activities, and effects on cell differentiation and proliferation. ${ }^{2 \cdot 4}$ Our observation that retinoids also may mobilise amyloid deposits in psoriasis has not to our knowledge been previously reported.

The mechanism behind secondary amyloidosis in psoriasis and other chronic inflammatory conditions is not fully understood, but a longstanding active inflammatory process is always present. For many years this patient suffered from inflammation with a prominent acute phase reaction. During treatment with retinoids her clinical and laboratory inflammatory activity 
decreased. The effect of etretinate on her amyloidosis possibly depends therefore on the anti-inflammatory activities of retinoids recently reviewed by Orfanos and Bauer ${ }^{3}$; inhibition of the mobility of granulocytes and their migration into the epidermis, reduction of DNA synthesis of human lymphocytes, and stimulation of monocytes and macrophages-inflammatory cells considered to be essential in the pathophysiology of psoriasis.

1 Dicken CH. Retinoids: a review. I Am Acad Dermatol 1984:4:541-51.

2 Fuchs E, Green $H$. Regulation of terminal differentiation of cultured human keratinocytes by vitamin A. Cell 1981;25:617-25.

3 Orfanos CE, Bauer R. Evidence for anti-inflammatory activities of oral synthetic retinoids: experimental findings and clinical experience. Br $\mathcal{F}$ Dermatol 1983;109:55-60.

4 Plewig G. Wagner A. Anti-inflammatory effects of 13-cis-retinoid acid. Arch Dermatol Res 1981:270:89-94.

Acccepted 23 7une 1986

Departments of Internal Medicine and Dermatology, University Hospital, S-751 85 Uppsala, Sweden

EVA AF EKENSTAM, MD, registrar in rheumatology

GERD MICHAËLSSON, MD, PHD, associate professor of dermatology

ROGER HÄLLGREN, MD, PHD, associate professor of internal medicine

Correspondence to: Dr Eva af Ekenstam, Section of Rheumatology, Department of Internal Medicine, University Hospital, S-751 85 Uppsala, Sweden.

\section{Pancreatitis induced by oestrogen in a patient with type I hyperlipoproteinaemia}

Type I hyperlipoproteinaemia (familial hyperchylomicronaemia) is a disorder in the catabolism of triglyceride rich particles caused by a genetic deficiency of lipoprotein lipase or its cofactor apolipoprotein CII. Pancreatitis is a frequent and dangerous complication. We report on a patient with this disorder who suffered from pancreatitis during the use of an oral contraceptive.

\section{Case report}

The 25 year old patient had undergone laparotomy because of a chyloperitoneum at the age of 6 weeks. At that time milky serum, hepatosplenomegaly, and a chylothorax were found. A fat restricted diet was prescribed, and she grew up normally with no complaints. Serum cholesterol concentrations varied between 5 and $8 \mathrm{mmol} / \mathrm{l}(193-309 \mathrm{mg} / \mathrm{dl})$ and serum triglyceride concentrations between 10 and $30 \mathrm{mmol} / \mathrm{l}(885-2655 \mathrm{mg} / \mathrm{dl}$ ) (figure).

Between the ages of 22 and 25 she was admitted to the hospital eight times because of pancreatitis, indicated by raised amylase activity in plasma and urine. Serum triglyceride concentrations up to $30-40 \mathrm{mmol} / \mathrm{l}(2655-3540 \mathrm{mg} / \mathrm{dl})$ were found, but these may be underestimations because on several occasions concentrations were measured only on the second or third day after admission. During

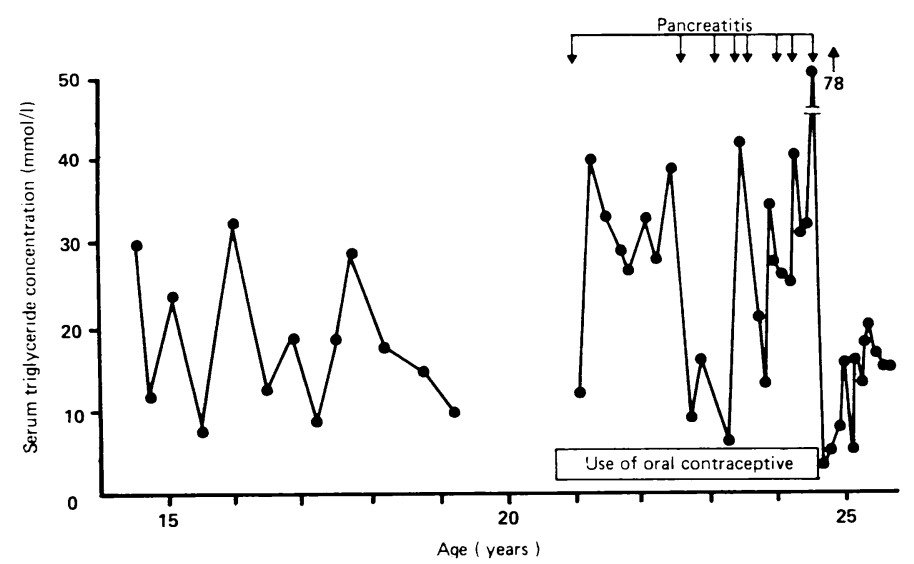

Serum triglyceride concentrations and attacks of pancreatitis in patient with type I hyperlipoproteinaemia.

Conversion: SI to traditional units-Serum triglyceride: $1 \mathrm{mmol} / \mathrm{l} \approx 88.5 \mathrm{mg} / \mathrm{dl}$. the last attack of pancreatitis abdominal abscesses were found during a laparotomy.

After recovery the patient was referred to our clinic. She said that she followed a low fat diet and denied using ethanol. Until three months previously, however, she appeared to have been using an oral contraceptive containing $150 \mu \mathrm{g}$ levonorgestel and $30 \mu$ g ethinyloestradiol, from the age of 21 to 25 years. There was no xanthomas. Liver and spleen were not palpable and blood glucose concentrations were normal. Fasting serum cholesterol concentration was 2.56 $\mathrm{mmol} / \mathrm{l}(99 \mathrm{mg} / \mathrm{dl})$ and triglyceride concentration $4 \cdot 16 \mathrm{mmol} / \mathrm{l}(368 \mathrm{mg} / \mathrm{dl})$. High density lipoprotein cholesterol concentration was $0.42 \mathrm{mmol} / 1(16 \mathrm{mg} / \mathrm{dl})$. Lipoprotein lipase activity was selectively measured in postheparin plasma ( 50 $\mathrm{U} / \mathrm{kg}$ ) after inactivation of hepatic lipase by specific antiserum. ${ }^{2}$ Lipoprotein lipase activity and hepatic lipase activity were 0.3 and $6.6 \mu \mathrm{mol}$ of free fatty acids $\mathrm{ml} / \mathrm{h}$, respectively (mean (range) values for 15 normal women $8 \cdot 9(5 \cdot 8 \cdot 14 \cdot 1)$ and $16 \cdot 2(6 \cdot 5-27 \cdot 4) \mu \mathrm{mol} / \mathrm{ml} / \mathrm{h}$, respectively). On isoelectric focusing of very low density lipoproteins a normal amount of apolipoprotein CII was found. ${ }^{2}$ Because the attacks of pancreatitis seemed to be related to the use of the oral contraceptive its use was discouraged. During one year of follow up serum triglyceride concentrations dropped, and the patient remained free of abdominal complaints (figure).

\section{Comment}

Pancreatitis is a common manifestation in familial hyperchylomicronaemia and may be induced by insufficient adherence to a low fat diet or by pregnancy leading to very high serum triglyceride concentrations. ${ }^{1}$ The very high concentrations of plasma triglycerides during pregnancy are supposed to result from an increased hepatic secretion of very low density lipoprotein under the influence of oestrogen in addition to the impaired clearance of these particles from the blood. ${ }^{1}$ Oral contraceptives containing oestrogen may have the same effect. In the normal population oral contraceptives also increase serum triglyceride concentration. ${ }^{3}$ In other forms of familial hypertriglyceridaemia pronounced hyperlipidaemia and pancreatitis have also been associated with use of oral contraceptives ${ }^{45}$; however, such an association has not yet been reported in patients with type I hyperlipoproteinaemia.

Our patient had no problems when following a low fat diet, but when she started to use an oral contraceptive her hyperlipidaemia was aggravated and bouts of severe pancreatitis occurred. These drugs should therefore not be prescribed in patients with familial hyperchylomicronaemia and distinct hypertriglyceridaemia.

We thank Dr R Estourgie and Dr J Wils for providing clinical data. We also thank Mrs P van Heijst and H Hak-Lemmens for technical help and Mrs A Ruesen for preparing the manuscript.

1 Havel RJ, Goldstein JL, Brown MS. Lipoproteins and lipid transport. In: Bondy PK, Rosenberg LE, eds. Metabolic control and disease. Philadelphia: Saunders, 1980:393-494.

2 Stalenhoef AF, Casparie AF, Demacker PN, Stouten JT, Lutterman JA, van 't Laar A. Combined deficiency of apolipoprotein C-II and lipoprotein lipase in familial hyperchylomicronemia. Metabolism 1981;30:919-26.

3 Wallace RB, Hoover J, Barrett-Connor E, et al. Altered plasma lipid and lipoprotein levels associated with contraceptive and oestrogenic use. Report from the Medications Working Group of the Lipid Research Clinics Program. Lancet 1979;ii:111-5.

Glueck CJ, Scheel D, Fishback J, Steiner P. Estrogen induced pancreatitis in patients with previous covert type V hyperlipoproteinemia. Metabolism 1972;21:657-66.

5 Davidoff F, Tishler S, Rosoff C. Marked hvperlipidemia and pancreatitis associated with contraceptive therapy. N Engl f Med 1973;289:552-5.

Accepted 11 fuly 1986

Division of General Internal Medicine, Department of Medicine, University of Nijmegen, PO Box $9101,6500 \mathrm{HB}$, Nijmegen, Netherlands

$P M$ J STUYT, MD, consultant internist

P N M DEMACKER, PHD, biochemist

A F H STALENHOEF, MD, consultant internist

Correspondence to: Dr Stuyt.

\section{Correction}

Increased risk of sudden infant death syndrome in older infants at weekends

We regret that there was an error in the table in the short report by Murphy, Campbell, and Jones (9 August, p 364). In the right hand column (95\% confidence interval) the entry for Saturday should read $(1 \cdot 02-1 \cdot 16)$.

m 